\title{
CD40-activated B cells from patients with systemic lupus erythematosus can be modulated by therapeutic immunoglobulins in vitro
}

\author{
Sonia Néron ${ }^{1,2}$, Gilles Boire ${ }^{3}$, Nathalie Dussault ${ }^{1}$, Claudia Racine ${ }^{1}$, \\ Artur J. de Brum-Fernandes ${ }^{3}$, Serge Côté $^{1,2}$ and Annie Jacques ${ }^{1}$ \\ ${ }^{1}$ Héma-Québec, Recherche et développement, Ingénierie cellulaire, Québec, Québec, Canada \\ ${ }^{2}$ Département de biochimie et microbiologie, Faculté des sciences et de génie, Université Laval, Québec, Québec, Canada \\ ${ }^{3}$ Service de rhumatologie, Faculté de médecine et des sciences de la santé, Université de Sherbrooke \\ et Centre hospitalier universitaire de Sherbrooke, Sherbrooke, Québec, Canada
}

Received: 2009.02.10, Accepted: 2009.04.29, Published online: 2009.10.29

(C) L. Hirszfeld Institute of Immunology and Experimental Therapy, Wrocław, Poland 2009

\begin{abstract}
Introduction: Aberrant signaling within and between $\mathrm{B}$ and $\mathrm{T}$ cells, considered to be central in systemic lupus erythematosus (SLE), could depend on enhanced CD40-CD154 activation. As a result, autoreactive B cells, normally anergic, differentiate and secrete antibodies attacking several normal tissues. Thus restorating B cell homeostasis might help control this disease. In this study, two facets of SLE B cells were investigated, namely their in vitro response to CD40-CD154 and the effect of treatment with human immunoglobulins for intravenous use (IVIg).

Materials and Methods: Blood samples from SLE patients and healthy volunteers were obtained and used to isolate B cells, which were activated through CD40 in the presence or absence of IVIg. The phenotype, proliferation, and differentiation of the SLE B cells were determined and compared with those of control B cells using flow cytometry and standard ELISA.

Results: In this model, CD40-activated SLE B cells, as control B cells, proliferated and differentiated and were characterized by the emergence of $\mathrm{CD} 19^{\text {lo }} \mathrm{CD} 38^{++} \mathrm{CD} 138^{+} \mathrm{CD} 27^{++}$cells. IVIg treatment of the CD40-activated SLE B cells resulted in higher differentiation, characterized by increased secretion rates of $\operatorname{IgG}$ and $\operatorname{IgM}$, as reported previously for control B cells.

Conclusions: Taken as a whole, such accelerated differentiation of CD40-activated B cells suggests that IVIg may participate in re-equilibration of the antibody repertoire by replacing pathological antibodies by de novo harmless antibodies.
\end{abstract}

Key words: B cell, SLE; differentiation, intravenous immunoglobulins, IVIg.

Corresponding author: Sonia Néron, Ph.D., Recherche et développement, Héma-Québec, 1070, avenue des Sciences-de-la-vie, Québec, Qc, G1V 5C3, Canada, tel.: +1 418-7804362 (ext. 3260), fax: +1 418-7802101, e-mail: sonia.neron@hema-quebec.qc.ca

\section{INTRODUCTION}

Systemic lupus erythematosus (SLE) is a complex autoimmune disease with heterogeneous clinical manifestations [reviewed in (Zimmerman et al. 2001)]. Lymphopenia is commonly observed in SLE manifested by decreased numbers of $\mathrm{T}$ cells, including $\mathrm{CD}^{+}$and $\mathrm{CD}^{+}$cells (Wouters et al. 2004), as well as B cells (Odendahl et al. 2000). Homeostasis within peripheral B cells from SLE patients is disturbed and can be characterized by an increased frequency of $\mathrm{CD} 27^{+}$cells (Odendahl et al. 2000; Jacobi et al. 2003). SLE patients with active disease have a higher frequency of circulating blood plasma cells (Harada et al. 1996; Jacobi et al. 2003). Aberrant levels of soluble or surface molecules involved in B-cell activation, such as interleukin (IL)-10, BAFF, CD40, and CD154 (Gonzalez-Amaro et al. 1998; Sun et al. 2000; Zouali 2005), as well as enhanced calcium release, defective FcyRIIB signaling, and reduced expression of Lyn [reviewed in (Pugh-Bernard and Cambier 2006)] can all be observed in SLE. Overall, SLE is caused by multiple immune dysregulations involving several cell populations, in which B-cell dysfunction, leading to a general B-cell hyperactivity, appears to be a central element [reviewed in (Mandik-Nayak et al. 2008)].

Autoantibodies observed in the serum of SLE 
patients include IgG specific to dsDNA (Klinman et al. 1994). Anti-dsDNA antibodies from SLE patients are often derived from the $\mathrm{V}_{\mathrm{H}^{4}}$-34 gene, characterized by the 9G4 idiotype, which has been proposed as a marker of disease severity (Cappione et al. 2004; Isenberg et al. 1998; Pugh-Bernard et al. 2001). For instance, these anti-dsDNA antibodies are particularly associated with renal damage (Putterman 2004), and an increased frequency of CD27- memory B cells carrying the 9G4 idiotype has recently been reported to correlate with increased disease activity (Wei et al. 2007).

In many autoimmune disorders, IVIg treatment results in the suppression of pathological autoimmune antibodies in patient serum for prolonged periods of time (Branch et al. 2001; Kaveri et al. 1991). Since IVIg contains anti-idiotypic antibodies capable of binding to these pathological autoantibodies, many authors have postulated that IVIg can directly and specifically modulate autoreactive B cells (Kazatchkine et al. 1994; Seite et al. 2008; Sherer and Shoenfeld 2006b; Shoenfeld and Katz 2005; Vani et al. 2008) and by doing so restore immune homeostasis in patients with autoimmune diseases. The use of IVIg in the treatment of SLE can result in partial to complete remission in patients with various manifestations of SLE [reviewed in (ZandmanGoddard et al. 2005)]; however, its use is often restricted to SLE patients who did not respond to standard treatment (Sherer and Shoenfeld 2006a). The antiinflammatory properties of IVIg have been invoked to explain its therapeutic effects in the treatment of autoimmune diseases, including SLE (Anthony et al. 2008). Alternatively, a possible connection between the immunomodulatory mechanisms of IVIg and SLE treatment could involve blockade of BAFF through antiBAFF (Le Pottier et al. 2007; Toubi and Shoenfeld 2004a; Vani et al. 2008) or neutralization of pathogenic anti-dsDNA through anti-idiotypic antibodies, as reported in mouse models (Shoenfeld et al. 2002).

In the course of an immune response, B cells proliferate and form germinal centers in lymph nodes (McHeyzer-Williams et al. 2006). This step requires the stimulation of CD40 expressed on B cells by its ligand CD154 expressed on activated T cells (Van Kooten and Banchereau 2000). There is good evidence that dysfunction in the CD40-CD154 interaction contributes to SLE pathogenesis (Grammer et al. 2003; Toubi and Shoenfeld 2004b), as demonstrated in clinical trials investigating treatment with humanized anti-CD154 antibodies, even though these trials have not been successful due to adverse side effects (Driver et al. 2008).

In humans, the study of B-cell activation via CD40 can be done using an in vitro model based on feeder cells stably transfected with CD154 supplemented with cytokines (Banchereau et al. 1991; Néron et al. 2005). We previously showed that IVIg modulates the proliferation and differentiation of CD40-activated human B cells and observed IVIg-specific enhancement of secreted anti-dsDNA and anti-IgG $\mathrm{F}\left(\mathrm{ab}^{\prime}\right)_{2}$ fragments (de Grandmont et al. 2003). Here we report that in vitro
CD40 activation of B cells from SLE patients leading to high expansion and differentiation can also be modulated by IVIg treatment, resulting in decreased proliferation and increased differentiation into Ig-secreting cells.

\section{MATERIALS AND METHODS}

\section{SLE patients}

Eligible subjects were adult women or men, aged $\geq 18$ years, who met the American College of Rheumatology criteria for the definition of SLE (Gladman et al. 2000). Disease activity in these patients was defined using the Systemic Lupus Erythematosus Disease Activity Index (SLEDAI) on the day of blood collection ( Hawker et al. 1993; Hochberg 1997; Gladman et al. 2000; Liang et al. 1989). Organ damage resulting from SLE was assessed according to the ACR/SLICC Index (Gladman et al. 2000). Treatments received by each patient were noted on the day of blood collection; no exclusions based on treatment allocation (e.g. cyclophosphamide or prednisone) were made in this study.

\section{Blood sample collection from SLE patients and healthy individuals}

Blood samples were collected from SLE patients after informed consent following approval by the Research Ethics Board of the Centre hospitalier universitaire de Sherbrooke and the Research Ethics Committee of Héma-Québec. Whole blood samples were collected from SLE patients in heparinized tubes (Vacutainer, Becton Dickinson, Franklin Lakes, NJ, USA). A maximum of 14 tubes from each patient were collected, pooled, and diluted in one volume of $10 \mathrm{mM}$ phosphate-buffered saline, $\mathrm{pH}$ 7.4. Leukocytes from healthy individuals were recovered from leukoreduction systems, as described previously (Néron et al. 2006; Néron et al. 2007), after informed consent and following approval by the Research Ethics Committee of HémaQuébec. Peripheral blood mononuclear cells (PBMCs) were prepared from patients and controls by density centrifugation over Ficoll-Paque (GE Healthcare Bio-Sciences Inc., Baie d'Urfé, QC, Canada) (Fecteau and Néron 2003) and stored frozen until B-cell purification. About $50-100 \times 10^{6}$ cells were recovered from each SLE sample.

\section{CD40 stimulation of peripheral B cells}

B cells were purified as described previously (Néron et al. 2005) and seeded at 300,000 cells/ml in Primaria plates (Becton Dickinson) in the presence of $\gamma$-irradiated L4.5 cells expressing CD154 (Néron et al. 1996; Roy et al. 2001). About 5 or 25 B cells were seeded per L4.5 cell to achieve high and low levels of CD154-CD40 interaction (Néron et al. 2005), respectively, in the pres- 
ence of $50 \mathrm{U} / \mathrm{ml}$ IL-2, 25 U/ml IL-10 (PeproTech, Rocky Hill, NJ, USA), $100 \mathrm{U} / \mathrm{ml}$ IL-4 (R\&D Systems, Minneapolis, MN, USA) and, where indicated, $25 \mathrm{ng} / \mathrm{ml}$ BAFF (PeproTech). Viable cell counts were evaluated in triplicate by Trypan blue dye exclusion using a hemacytometer.

\section{Intravenous immunoglobulin preparations}

Gamunex $^{\mathrm{TM}}$ intravenous immunoglobulin preparation (IVIg) from Bayer Inc. (Toronto, Ont., Canada) and bovine serum albumin (BSA, Cohn fraction V, Sigma, St. Louis, MO, USA) were dialyzed against 10 $\mathrm{mM}$ potassium/sodium phosphate with $136 \mathrm{mM} \mathrm{NaCl}$ (Invitrogen) containing $40 \mathrm{mM}$ glycine, $\mathrm{pH} 4.5$ (Sigma) (de Grandmont et al. 2003; Dussault et al. 2008). BSA, which does not interfere with B-cell proliferation and Ig secretion (de Grandmont et al. 2003), was used as a control of protein content at concentrations equivalent to IVIg.

\section{Flow cytometric analyses}

PerCP-cyanin 5.5-anti-CD19, allophycocyanin-conjugated anti-CD19, anti-CD21, or anti-CD38, PE-conjugated anti-CD27, anti-CD40, or anti-CD138, FITC-conjugated anti-CD27 or anti-IgG, and the PerCP-cyanin 5.5-, allophycocyanin-, PE-, and FITC-conjugated isotype controls were $\mathrm{IgG}_{1}$ mouse $\mathrm{mAbs}$ obtained from $\mathrm{BD}$ Biosciences (Mountain View, CA, USA). The $\mathrm{V}_{\mathrm{H}} 4-34-$ -specific anti-idiotype mAb 9G4, kindly provided by Dr. Freda Stevenson (Tenovus Research Laboratories, Southampton, UK), was used in indirect staining with FITC-conjugated goat F(ab') ${ }_{2}$ anti-rat IgG. Cells were fixed with $2 \%$ paraformaldehyde and $>95 \%$ of the cells were double-negative with isotype-matched control Abs. Intracellular IgG content was determined on fixed cells permeabilized with $0.1 \%$ saponin. Dot-plot regions containing dead cells were delineated using 7-amino-actinomycin D staining following the manufacturer's instructions (BD Bio-sciences) and all analyses were done on viable cells only. Data acquisition was done by gating $>80,000$ cells for PBMCs or $>5000$ for purified $\mathrm{B}$ cells with a FACSCalibur flow cytometer and CellQuest Pro software (BD Biosciences). Data were subsequently analyzed using FCS express II (De Novo Software, Thornhill, ON, Canada).

\section{IgG and IgM secretion rates}

B cells were harvested and extensively washed using $10 \mathrm{mM}$ phosphate-buffered saline, $\mathrm{pH}$ 7.4. For IVIg-treated cells, the assayed IgG and IgM concentrations in the last washing supernatants were found to be negligible in all cases $(<5-10 \mathrm{ng} / \mathrm{ml} / \mathrm{h})$. Cells were seeded at $1-2 \times 10^{6}$ cells/ml in IMDM medium without added cytokines and CD154-expressing cells for 6-24 h. IgG and IgM concentrations were determined using a standard ELISA (Fecteau and Néron 2003).
Statistical analysis

The mean values \pm SD were calculated for the groups of SLE patients and healthy controls (HC). The data distribution was evaluated using the Shapiro-Wilk test and analysis of variance was done using the $F$ test. Thereafter, statistical significance between patients and controls was determined using the Mann-Whitney $U$ test, two-sided Student's unpaired $t$ test, or the Satterthwaite test.

\section{RESULTS}

\section{SLE peripheral blood B cells respond to low CD154 interaction}

To study the response of SLE B cells to in vitro CD40 stimulation, we applied conditions that allow the expansion and differentiation of both naïve and memory B cells (Néron et al. 2005). Purified B cells obtained from 12 SLE patients were stimulated under conditions of low CD40-CD154 interaction in the presence of a mixture of IL-2, IL-4, and IL-10 for 9-14 days (Table $1, n=12)$. All the samples tested responded to CD40 activation by proliferation, as shown by $\mathrm{T}_{\text {gen }}$ ranging from $29-77 \mathrm{~h}$. In addition, the viability of the activated B cells was maintained above $79 \%$ in all assays. Under these conditions, $T_{\text {gen }}$ and viability of the SLE samples were not significantly different from those of the B cells from the HC. No obvious correlation could be discerned between disease severity, which was generally moderate (SLEDAI $\leq 9)$, and the level of SLE B-cell response to CD40 stimulation. The diverse medication regimens administered to the SLE patients did not influence the response capacity of their B cells in culture. Three representative examples of the results presented in Table 1 (sample no. 5, 17, and 19) illustrating the expansion of SLE B cells compared with HC B cells are shown in Fig. 1. For all 12 samples listed in Table 1, the SLE B cells showed proliferation similar to that observed for the HC cells when maintained for culture periods of 9 or 13 days. The SLE B cells were characterized by elevated IgG and IgM secretion rates (Fig. 1B) which were at least similar to or higher than those of $\mathrm{HC} B$ cells. Overall, under these culture conditions the IgG secretion rates of the SLE B cells were about 8-fold higher than those of $\mathrm{IgM}$, reaching $1 \mu \mathrm{g} / 10^{6}$-cells/h. These observations suggest that SLE B lymphocyte activation status was somewhat similar to that of the control cells. The SLE samples (Fig. 1C) showed higher frequencies of $\mathrm{CD} 27^{+}$cells than the HC samples after long-term stimulation, indicating a possible bias in the SLE B lymphocyte populations. Overall, these observations suggest that the in vitro response of SLE B cells to CD40 activation might represent a good reflection of their in vivo activation status, characterized by high Ig secretion and a sustained CD40-dependent proliferative response. 
Table 1. B cells isolated from PBMCs obtained from patients with SLE proliferate in response to sustained CD40 activation

\begin{tabular}{|c|c|c|c|c|c|c|}
\hline \multicolumn{3}{|c|}{ Patients } & \multicolumn{2}{|c|}{ Disease activity indices ${ }^{3}$} & \multicolumn{2}{|c|}{ CD40 activation ${ }^{4}$} \\
\hline No. & Criteria $^{1}$ & Treatment $^{2}$ & SLEDAI & ACR/SLICC & $\begin{array}{l}\text { Viability } \\
(\%)\end{array}$ & $\begin{array}{l}\mathrm{T}_{\text {gen }} \\
(\mathrm{h})\end{array}$ \\
\hline 1 & 8 & $\mathrm{~A}, \mathrm{C}, \mathrm{I}$ & 6 & 0 & $88 \pm 4$ & 65 \\
\hline 2 & 4 & $\mathrm{~A}, \mathrm{O}$ & 2 & 0 & $81 \pm 6$ & 61 \\
\hline 5 & 7 & $\mathrm{~A}, \mathrm{C}, \mathrm{I}, \mathrm{O}$ & 5 & 1 & $89 \pm 6$ & 46 \\
\hline 9 & 6 & $\mathrm{~A}, \mathrm{C}, \mathrm{I}, \mathrm{O}$ & 8 & 6 & $88 \pm 6$ & 57 \\
\hline 10 & 6 & $\mathrm{~A}, \mathrm{I}, \mathrm{O}$ & 0 & 1 & $79 \pm 6$ & 39 \\
\hline 11 & 6 & $\mathrm{~A}, \mathrm{O}$ & 0 & 0 & $88 \pm 7$ & 74 \\
\hline 12 & 4 & $\mathrm{O}$ & 2 & 0 & $91 \pm 4$ & 36 \\
\hline 17 & 5 & $\mathrm{~A}, \mathrm{C}, \mathrm{O}$ & 0 & 0 & $94 \pm 3$ & 77 \\
\hline 19 & 4 & $\mathrm{~A}, \mathrm{O}$ & 0 & 0 & $85 \pm 10$ & 33 \\
\hline 24 & 7 & $\mathrm{~A}, \mathrm{I}$ & 3 & ND & $91 \pm 3$ & 9 \\
\hline 26 & 4 & $\mathrm{O}$ & 0 & 3 & $88 \pm 5$ & 68 \\
\hline 32 & 7 & $\mathrm{~A}, \mathrm{I}, \mathrm{O}$ & 9 & 1 & $90 \pm 6$ & 29 \\
\hline \multicolumn{2}{|c|}{$\operatorname{SLE}(n=12)^{5}$} & & - & & $88 \pm 6$ & $53 \pm 16$ \\
\hline \multicolumn{2}{|c|}{$\mathrm{HC}(\mathrm{n}=12)^{5}$} & & - & & $90 \pm 9$ & $52 \pm 24$ \\
\hline
\end{tabular}

${ }^{1}$ Number of criteria according to the American College of Rheumatology classification (Hochberg 1997); ND: not determined.

${ }^{2}$ Treatments are designated as immunosuppressant (I) such as azathioprine, cyclosporine or mycophenolate mofetil, corticosteroids (C) (mainly prednisone), antimalarial (A) (mainly hydroxychloroquine sulphate), and others (O).

${ }^{3}$ SLEDAI: disease activity indices (Hawker et al. 1993; Liang et al. 1989); ACR/SLICC Assessment of organ damage (Gladman et al. 2000).

${ }^{4} \mathrm{CD} 19^{+} \mathrm{B}$ cells were exposed to a low level of CD154 stimulation in the presence of IL-2, IL-4, and IL-10 for 9 to 14 days. The average viability $(\%)$ of stimulated cells is shown and the generation time $\left(\mathrm{t}_{\mathrm{gen}}\right)$ was calculated within the exponential phase of the growth curve using the formula $\kappa=1 / \ln 2\left(\ln \left[\mathrm{N}_{\mathrm{t} 2}\right]-\ln \left[\mathrm{N}_{\mathrm{t} 1}\right]\right) / \mathrm{t}_{2}-\mathrm{t}_{1}$ and $\mathrm{t}_{\mathrm{gen}}=1 / \kappa$

${ }^{5}$ Mean values for generation time and viability are given for SLE and healthy control (HC) B cells and are not significantly different from each other according to Student's $t$ test.

\section{$C D 138^{+}$cells are present at high frequencies in mononuclear cells from SLE patients with low to moderate disease activity}

High frequencies of $\mathrm{CD} 27^{+}, \mathrm{CD} 38^{++}$, and CD138 cells are observed in patient blood showing highly active SLE disease (Harada et al. 1996; Odendahl et al. 2000; Sato et al. 2004). In this study, the disease severity of most of the SLE participants was moderate (SLEDAI $\leq 9$ ), with only a few cases reaching a level of 12 . Despite the limited number of severe cases, given the relevance of these B-cell differentiation markers we determined the frequencies of CD19-, CD27-, CD38-, and CD138-positive cells within the PBMCs of 10 SLE patient samples by flow cytometry (Table 2). The frequencies of $\mathrm{CD} 19^{+}$cells and $\mathrm{CD} 27^{+} \mathrm{B}$ cells, ranging respectively from $2-15 \%$ and $15-48 \%$, were not significantly different from the values obtained with $\mathrm{HC}$ cells and similar to those previously reported for healthy individuals (Néron et al. 2006). In contrast, the frequency of $\mathrm{CD} 138^{+}$cells, ranging from $1.4-10 \%$, was well above normal ranges $(\mathrm{p}<0.002)$ compared with $\mathrm{HC}(0.5 \pm 0.4 \%)$, which were close to the expected normal frequency of $0.5 \%$ (Harada et al. 1996). These $\mathrm{CD} 138^{+}$cells expressed CD27 at intermediate levels (mean fluorescence intensity, MFI: $35 \pm 15$ ) and a fraction of the cells (6-43\%) maintained CD19 expression, indicating that the cells were in transition toward final differentiation. Worthy of note, only a fraction $(44 \pm 10 \%)$ of the $\mathrm{CD} 138^{+}$cells present in the $\mathrm{HC}$ samples expressed
CD27. In addition, the proportion of B cells expressing high levels of CD38 was also significantly higher $(\mathrm{p}<0.008)$ in SLE $(15 \pm 10 \%)$ than in HC $(5 \pm 4 \%)$. These observations suggest that the presence of $\mathrm{CD} 27^{+} \mathrm{CD} 138^{+}$ and $\mathrm{CD} 38^{++}$cells at higher frequencies is a distinctive feature of SLE peripheral blood cell populations, even in patients with moderate disease activity.

\section{SLE B cells show a low level of differentiation into $\mathrm{CD} 138^{+}$cells}

We previously reported that a low level of CD40 activation can drive $\mathrm{B}$ cells toward differentiation into plasma cells expressing CD138 (Néron et al. 2005). To further investigate $\mathrm{CD} 138^{+}$cell populations in vitro, $\mathrm{CD} 40$ -induced responses of SLE B cells from three patients with the respective SLEDAIs of 0,8 , and 12 were compared with those of control cells exposed to the same conditions for nine days, after which CD19, CD27, and CD138 expression was determined by flow cytometry (Fig. 2). As previously reported (Néron et al. 2005), in vitro activation of $\mathrm{HC} \mathrm{B}$ cells using a low level of CD40 stimulation in the presence of a mixture of IL-2, IL-4, and IL-10 resulted in high proportions of CD27 ${ }^{+}(33 \%)$ and $\mathrm{CD} 138^{+}(23 \%)$ cells. Likewise, CD27 and CD138 frequency appeared lower in SLE B cells than in HC $\mathrm{B}$ cells, ranging from $7-19 \%$ and 1-9\%, respectively (Fig. 2A). However, $\mathrm{CD} 38^{++} \mathrm{CD} 138^{+}$cells, as defined by gate 2 in Fig. 2, were also $\mathrm{CD} 27^{+} \mathrm{CD} 19^{\text {lo }}$ and thus correspond 

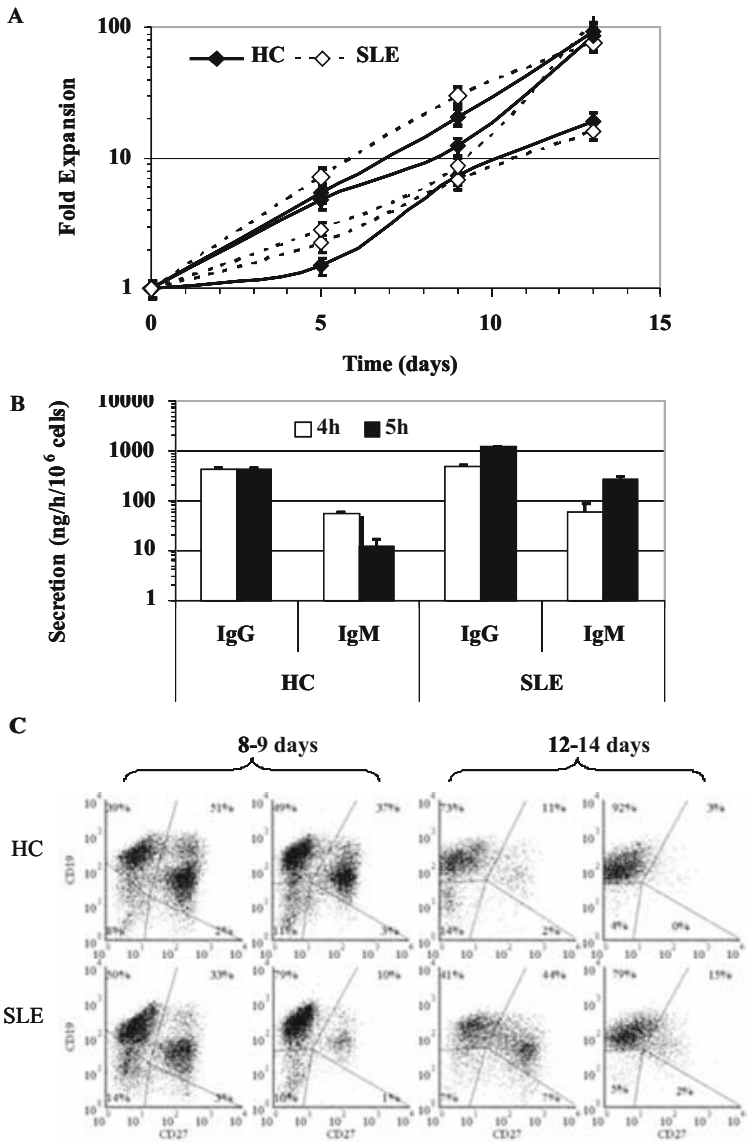

Fig. 1. CD40 activation of B cells from SLE patients induces high and sustained IgG and IgM secretion. B cells isolated from healthy controls (HC) or SLE patients were stimulated under conditions of low CD154 interaction in the presence of a mixture of IL-2, IL-4, and IL-10 for 14 days. (A) Cell counts were determined on the indicated days and used to evaluate total expansion, taking into account the expansion rate and the seeding cell density. These three paired sets of HC and SLE cultures were done at different times. Viability was $>90 \%$ for all samples throughout the culture period. SLE samples in this assay were from patient no. 5, 17, and 19, (cf. Table 1). (B) IgG and IgM secretion rates were measured at the end of the culture period using samples from SLE patient no. 5 and 19 and paired HC, over 5 and 4 h, respectively. Error bars for triplicate values can be smaller than symbols. This tendency was also observed in a supplemental paired culture of HC and SLE using samples from patient no. 23 (cf. Table 2). (C) B-cell phenotypes were compared on days 8 to 9 (samples from patient no. 24 and 26) or 13 to 14 (samples from patient no. 5 and 17) according to CD19 and CD27 expression in four independent experiments $(n=4)(\mathrm{cf}$. Table 1).

Table 2. High frequencies of $\mathrm{CD} 138^{+} \mathrm{CD} 27^{+}$cells within PBMCs in the samples from SLE patients

\begin{tabular}{|c|c|c|c|c|c|c|c|c|c|}
\hline \multicolumn{3}{|c|}{ Patients $^{1}$} & \multicolumn{2}{|c|}{$\operatorname{PBMC}^{2}(\%$ positive $)$} & \multicolumn{3}{|c|}{$\mathrm{CD} 19^{+}$cells $^{3}(\%)$} & \multicolumn{2}{|c|}{$\mathrm{CD} 138^{+} \mathrm{CD} 27^{+}$cells $^{4}$} \\
\hline No. & SLEDAI & ACR & CD19 & CD138 & $\mathrm{CD} 27$ & CD38 & $\begin{array}{c}\text { CD38hi } \\
(\mathrm{MFI})\end{array}$ & $\begin{array}{l}\text { CD19 } \\
(\%)\end{array}$ & $\begin{array}{l}\mathrm{CD} 27 \\
(\mathrm{MFI})\end{array}$ \\
\hline 3 & 0 & 7 & 5 & 1.4 & 38 & 66 & $21(263)$ & 14 & 47 \\
\hline 6 & 8 & 6 & 5 & 10 & 23 & 42 & $11(375)$ & 5 & 26 \\
\hline 14 & 4 & 4 & 4 & 3 & 48 & 50 & $3(347)$ & 6 & 34 \\
\hline 15 & 0 & 5 & 4 & 8 & 37 & 48 & $26(501)$ & 5 & 51 \\
\hline 16 & 8 & 7 & 10 & 7 & 41 & 46 & $11(313)$ & 12 & 54 \\
\hline 21 & 4 & 7 & 13 & 8 & 18 & 86 & $24(202)$ & 8 & 43 \\
\hline 22 & 4 & 5 & 2 & 2 & 25 & 77 & $13(281)$ & 6 & 47 \\
\hline 23 & 12 & 7 & 4 & 3 & 27 & 69 & $4(225)$ & 43 & 14 \\
\hline 24 & 3 & 7 & 8 & 2 & 15 & 66 & $29(205)$ & 33 & 22 \\
\hline 25 & 6 & 6 & 2 & 2 & 33 & 30 & $4(176)$ & 22 & 13 \\
\hline \multicolumn{3}{|c|}{$\begin{array}{l}\text { SLE }(n=10)^{5} \\
\text { Mean } \pm \text { SD }\end{array}$} & $6 \pm 4$ & $5 \pm 3$ & $31 \pm 11$ & $58 \pm 18$ & $15 \pm 10$ & $15 \pm 13$ & $35 \pm 15$ \\
\hline \multicolumn{3}{|c|}{$\begin{array}{l}\mathrm{HC}(\mathrm{n}=10)^{5} \\
\text { Mean } \pm \mathrm{SD}\end{array}$} & $9 \pm 4$ & $0.5 \pm 0.4$ & $31 \pm 12$ & $64 \pm 16$ & $5 \pm 4$ & $17 \pm 10$ & NA \\
\hline
\end{tabular}

${ }^{1}$ Disease activity indices and number of criteria according to ACR as reported in Table 1.

${ }^{2}$ Frequencies of B cells $\left(\mathrm{CD} 19^{+}\right)$and plasma cells $\left(\mathrm{CD} 138^{+}\right)$in PBMCs were determined by flow cytometry.

${ }^{3}$ The proportion of cells expressing CD27, CD38, as well as a high level of CD38 (CD38 ${ }^{\text {hi }}$ ) were determined within the gated $\mathrm{CD} 19^{+}$cell population. MFI: mean fluorescence intensity.

${ }^{4} \mathrm{CD} 138^{+}$cells from SLE samples all expressed CD27 (100\%); the proportion of CD19 (\%) as well as the level of CD27 expression (MFI) within $\mathrm{CD} 138^{+}$cells are shown.

${ }^{5}$ Mean and SD for SLE and healthy controls (HC) samples are shown for each cell subset. Significant differences between SLE and $\mathrm{HC}$ were observed for the frequencies of $\mathrm{CD} 138^{+}$cells $(\mathrm{p}<0.0002)$ and CD38 ${ }^{\text {high }}(\mathrm{p}<0.008)$. NA: not applicable, since $44 \pm 10 \%$ of the CD138+ cells from HC expressed CD27 (MFI; 102 \pm 22 ), as opposed to $100 \%$ of cells from SLE patients; this difference is statistically significant $(\mathrm{p}<0.0001)$, as determined by the Mann-Whitney test. 
A

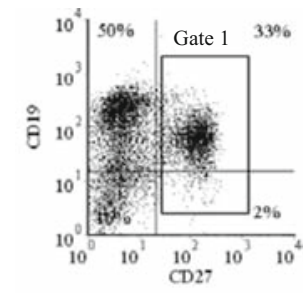

B

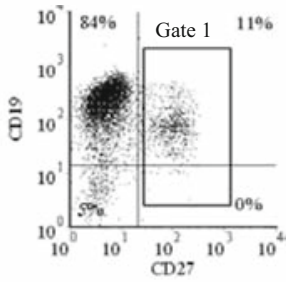

C

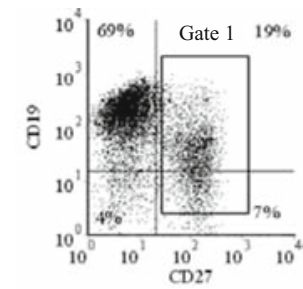

D

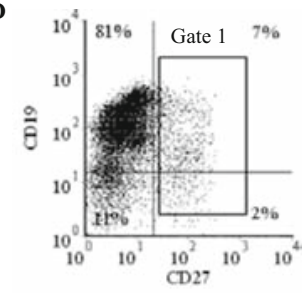

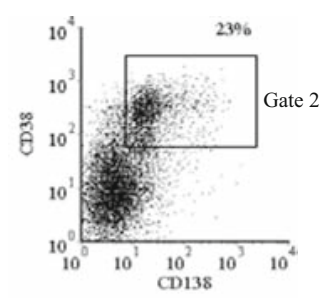
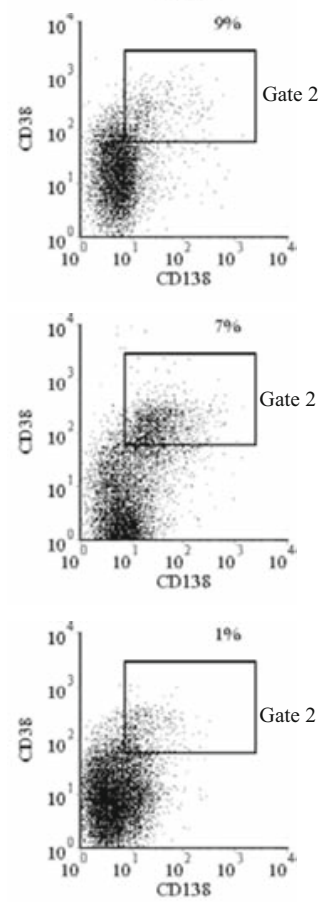

Fig. 2. The emergence of $\mathrm{CD} 138^{+}$cells following long-term stimulation of SLE B cells does not correlate with disease activity index. B cells isolated from a healthy control (A) or SLE patient nos. 26 (B), 9 (C), and 23 (D) with the respective SLEDAIs of 0, 8, and 12 were stimulated as described in Fig. 1 for 8 days. Cell phenotypes according to CD19, CD27, CD38, and CD138 were determined by quadruple-staining flow cytometry as described in Materials and Methods. On the day of sample collection, patient no. 9 was treated with mycophenolate mofetil and hydroxychloroquine sulfate, patient no. 23 with hydroxychloroquine sulfate and prednisone, and patient no. 26 only received anticoagulants. The events delineated by gate 2 correspond to $\mathrm{CD} 19^{\mathrm{lo}} \mathrm{CD} 27^{+} \mathrm{CD} 38^{++} \mathrm{CD} 138^{+}$cells.

to $\mathrm{CD} 19^{\text {lo }} \mathrm{CD} 27^{+} \mathrm{CD} 38^{++} \mathrm{CD} 138^{+}$cells in both $\mathrm{HC}$ and SLE samples. Collectively, these observations indicate that CD40-activated SLE B cells can differentiate into $\mathrm{CD} 138^{+}$cells in vitro; however, the proportion of CD138 $8^{+}$cells obtained after $8-9$ days of culture of SLE $\mathrm{B}$ cells was lower than that of $\mathrm{HC}$, which is in contrast to the high frequencies of $\mathrm{CD} 138^{+}$cells observed in the peripheral blood of SLE patients (Harada et al. 1996; Odendahl et al. 2000; Sato et al. 2004).

\section{SLE B-cell proliferation and differentiation} are both modulated in vitro by the addition of therapeutic immunoglobulins

Intravenous immunoglobulin injection to patients at doses of $0.4-2 \mathrm{~g} / \mathrm{kg}$ generally gives rise to an increase in

IgG blood concentration of about $5-10 \mathrm{mg} / \mathrm{ml}$ (Morell 1997; Negi et al. 2007). Based on our previous observations (de Grandmont et al. 2003; Dussault et al. 2008), SLE and HC B cells were treated with $10 \mathrm{mg} / \mathrm{ml}$ therapeutic immunoglobulin preparation (IVIg) using BSA as the protein supplement control (Fig. 3). To visualize whether there was a difference related to the level of activation, cell culture was performed under conditions of high CD40 stimulation in the presence of IL-4 alone (Fecteau and Néron 2003) and with low CD40 stimulation in the presence of IL-2, IL-4, and IL-10 (Néron et al. 2005). Overall, IVIg inhibited the expansion of HC and SLE B cells under both the high (2- to 4-fold) and low (1.5- to 2.5 -fold) CD40 stimulation conditions (Figs. $3 \mathrm{~A}$ and B). Compared with HC B cells, SLE B cells showed higher secretion of IgG and IgM by a factor of up to 6-fold under both conditions. The inhibitory effects of IVIg on cellular expansion can in fact be associated with enhanced IgM and IgG secretion rates (Figs. $3 \mathrm{C}$ and $\mathrm{D}$ ). Indeed, IVIg-induced modulation of IgG secretion was about 5 -fold and 3 -fold in cells receiving high and low CD40 stimulation, respectively, for both control and SLE B cells. Additionally, the effect of IVIg on IgM secretion appeared higher for SLE B cells (3-fold) compared with controls (<1.7-fold) (Fig. 3C). Overall, these observations show that in vitro treatment of SLE B cells with IVIg results in decreased proliferation and increased differentiation, as previously reported for B cells from healthy individuals (de Grandmont et al. 2003).

The frequency of $\mathrm{CD} 138^{+}$cells is slightly increased following IVIg treatment

B cells stimulated under conditions of low CD40 interaction, as defined above, were then monitored for the emergence of $\mathrm{CD} 138^{+}$cells following treatment with IVIg (Fig. 4). The frequency of $\mathrm{CD} 138^{+}$cells, of phenotype $\mathrm{CD} 19^{\mathrm{lo}} \mathrm{CD} 27^{+} \mathrm{CD} 38^{++}$as specified in Fig. 2, was slightly increased when SLE and HC B cells were treated with IVIg. The $\mathrm{CD} 38^{+}$and $\mathrm{CD} 27^{+}$populations were also increased to a similar extent in both SLE and HC B cells. Although interindividual differences were observed, these results indicate that IVIg treatment might modulate a small fraction of B cells to differentiate into Ig-secreting cells.

\section{IVIg treatment increases the proportion of $9 G 4^{+}$cells in SLE and control B cells}

The 9G4 idiotype characterizes a small population of $\mathrm{B}$ cells that are often linked to anti-dsDNA antibodies in SLE (Anolik et al. 2004; Isenberg et al. 1998). SLE disease is also characterized by sustained lymphocyte stimulation, based on a high CD154 expression on $\mathrm{T}$ cells (Toubi and Shoenfeld 2004b) as well as an increased concentration of BAFF (Tangye et al. 2006; Zhang et al. 2001). Based on these studies, we further investigated the effect of IVIg treatment on B cells 
A

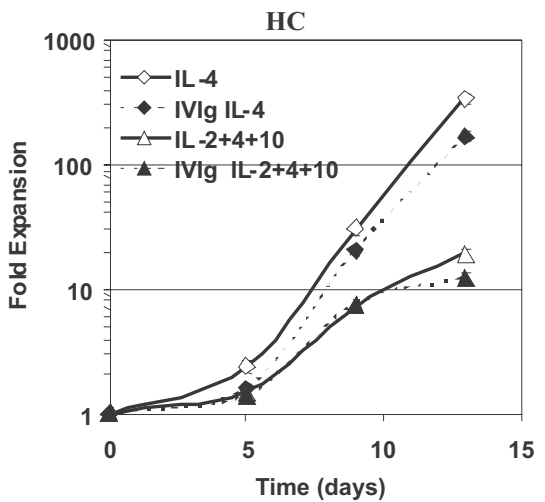

C

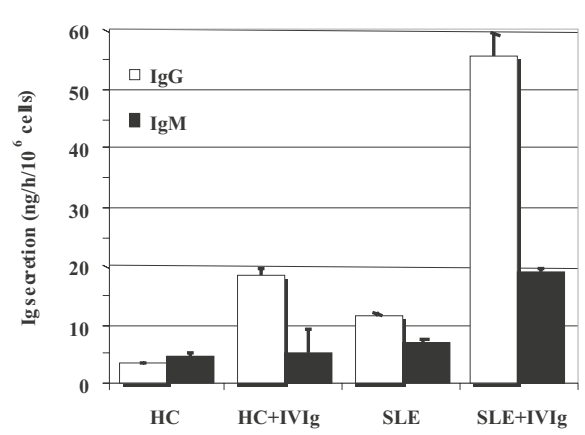

B

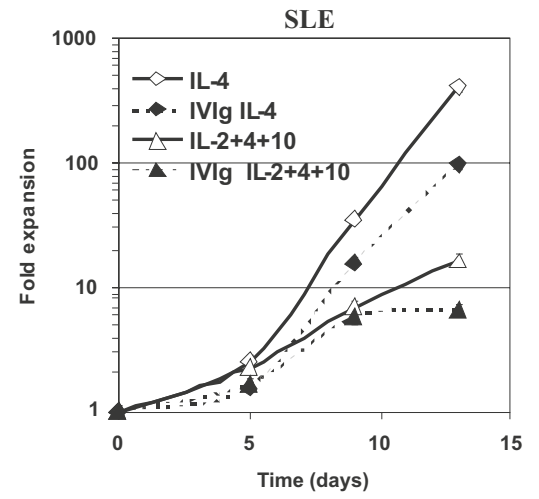

D

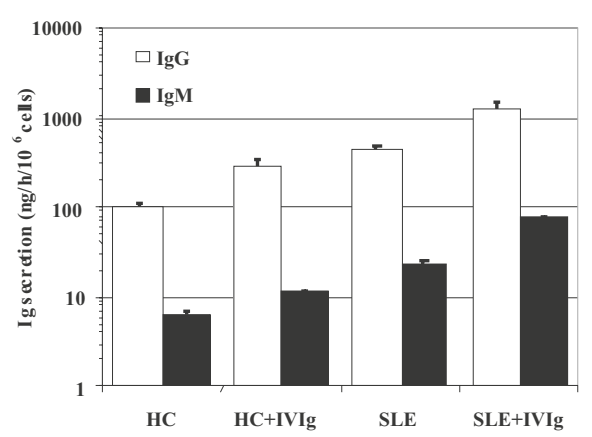

Fig. 3. IVIg treatment modulates the proliferation and differentiation of SLE B cells. Purified B cells were exposed to conditions of high CD154 interaction in the presence of IL-4 alone or low CD154 interaction in the presence of a mixture of IL-2, IL-4 , and IL-10 for 13 days with or without $10 \mathrm{mg} / \mathrm{ml} \mathrm{IVIg}$, as indicated. Expansion of B cells from (A) healthy controls (HC) or (B) an SLE patient (no. 17) was determined on the indicated days. Viability was $>90 \%$ for all samples during the culture period. The same tendency were observed in an independent experiment done with samples from two other patients. IgG and IgM secretion rates were measured over $22 \mathrm{~h}$ for cells exposed to (C) high or (D) low CD154 conditions. The results in panels (C) and (D) are representative of the tendency observed in two other independent experiments done with samples from different patients with SLEDAIs $\leq 12$. The B cells used in B, C, and D were obtained from patient no. 17, 11, and 23 with SLEDAIs of 0,0 , and 12 , respectively. Error bars can be smaller than the symbols. under conditions of high CD40 stimulation in the presence of a mixture of IL-2, IL-4, IL-10, and BAFF and monitored the proportion of $9 \mathrm{G}^{+}$cells in three independent experiments (Fig. 5). As above (Fig. 3), the expansion of the IVIg-treated SLE B cells was reduced by at least 2-fold over the 14-day culture period (Fig. $5 \mathrm{~A}$ ), while IgM secretion rates were increased by about 2-fold (Fig. 5B). Under these conditions, IgG secretion by SLE and HC B cells was equivalent to that of IgM (100-200 ng/106 cells/h) but was not influenced by IVIg treatment ( $p>0.05$, data not shown). Once more, these IVIg-dependent modulations of expansion and secretion were also observed in HC B cells. However, flow cytometry analyses showed that the frequency of cells expressing the 9G4 idiotype was increased by about 2 and 4-fold for SLE and HC B cells, respectively, following IVIg treatment. Such IVIg-induced differences in the frequency of B cells expressing the 9G4 idiotype were significant in four independent experiments for both HC $(p<0.005)$ and SLE $(p<0.01)$ B cells. More specifically, IVIg-treated SLE and HC B cells showed $29 \pm 14 \%$ and $32 \pm 11 \% 9 \mathrm{G}^{+}$cells, respectively, while untreated SLE and HC B cells showed about $9 \pm 3 \%$ $9 \mathrm{G} 4{ }^{+}$cells. We also observed that the mean fluorescence intensity for 9G4 expression significantly decreased following IVIg addition $(p<0.005$, data not shown). These trends suggest that IVIg treatment of human B cells could induce changes inside the $9 \mathrm{G} 4^{+}$ populations.

\section{DISCUSSION}

Abnormal CD40-CD154 interaction between B and $\mathrm{T}$ cells is considered to be an important determinant of SLE disease severity (Grammer and Lipsky 2002; Toubi and Shoenfeld 2004b). In vitro treatment of SLE B cells with recombinant trimeric CD154 used as a single agent results in attenuated proliferation and higher Ig secretion compared with control B cells grown under similar conditions (Harigai et al. 1999). In this study we performed long-term activation of SLE B cells using interaction with $\mathrm{CD} 154^{+}$cells and cytokines. Our observations suggest that following CD154 stimulation, the long-term expansion and differentiation into $\mathrm{CD} 138^{+}$ cells of SLE B cells can be quite similar to that of B cells from healthy individuals. Such in vitro similarities support the hypothesis that SLE B-cell dysregulation depends on cooperation with other cells in their environment when CD40-CD154 binding is provided without restriction.

In contrast, $\operatorname{IgM}$ and $\operatorname{IgG}$ secretion by SLE B cells was, in many cases, higher than that of control B cells when exposed to either a low or a high level of CD40 stimulation. In addition, the frequency of $\mathrm{CD} 27^{+}$cells was higher in SLE B cells following long-term stimulation. These observations are in agreement with previous studies on SLE reporting higher frequencies of CD27+ blood B cells and plasma cells (Arce et al. 2001; Jacobi et al. 2003; Odendahl et al. 2000), which could be prone to rapid differentiation into Ig-secreting cells through 


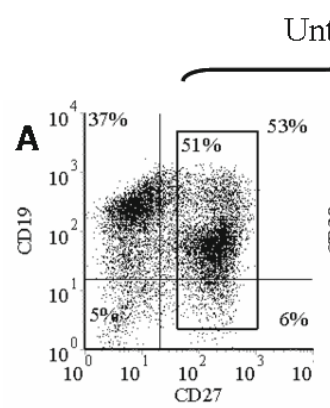

Untreated

IVIg
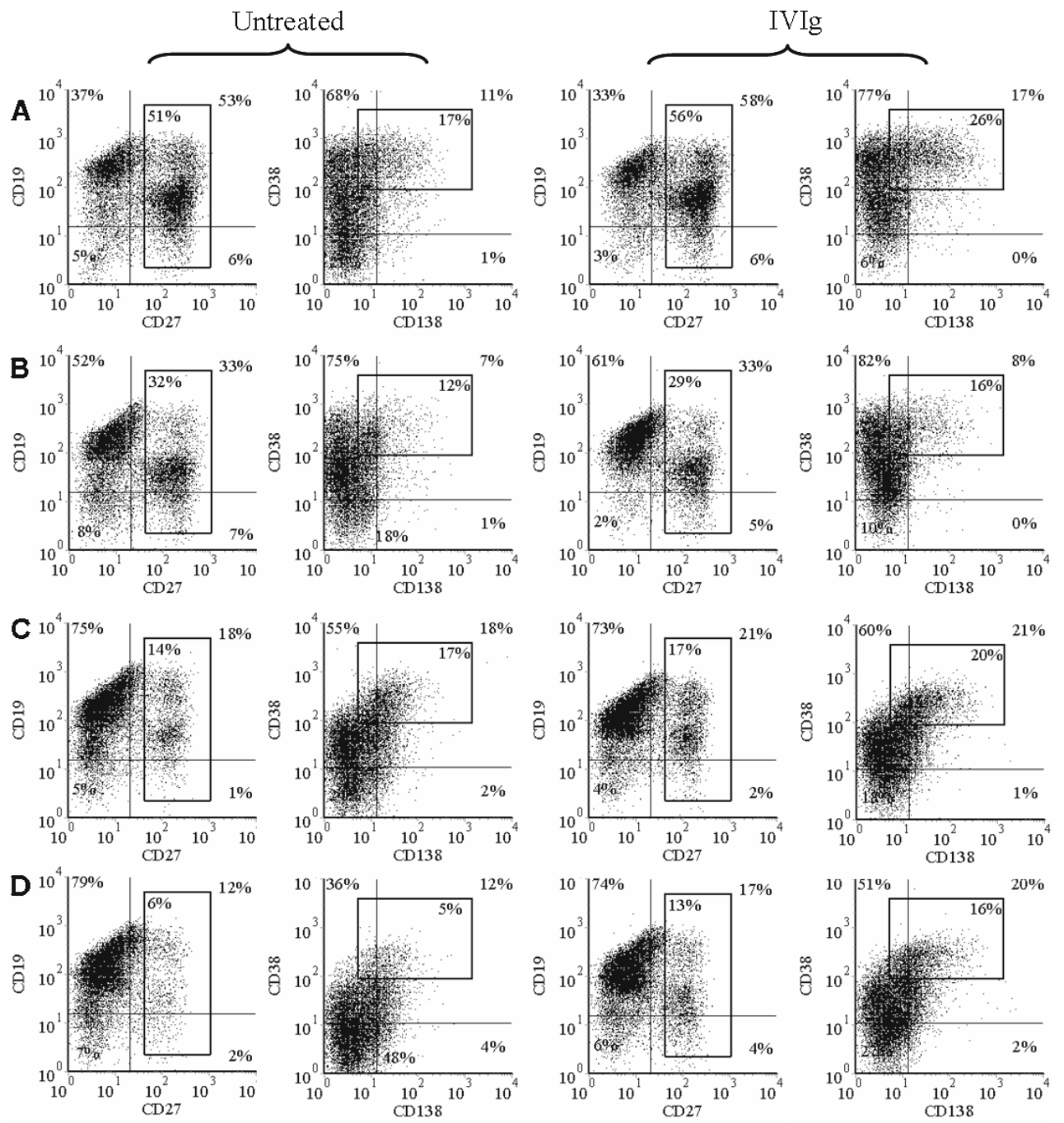

Fig. 4. IVIg modulates CD138 ${ }^{+}$cells in control and SLE B cells. B cells isolated from a healthy control (A, C) or SLE patients with the respective SLEDAIs of 3 (B) and 12 (D) were stimulated as described in Fig. 1 for 9 days in the absence or presence of $10 \mathrm{mg} / \mathrm{ml} \mathrm{IVIg}$. Cell phenotypes according to CD19, CD27, CD38, and CD138 were determined using quadruple-staining flow cytometry as described in Materials and Methods. As in Fig. 2, the cells defined by gate 2 were $\mathrm{CD} 19^{\mathrm{lo}} \mathrm{CD} 27^{+} \mathrm{CD} 38^{++} \mathrm{CD} 138^{+}$.

CD40-CD154 interaction (Nagafuchi et al. 2003). Collectively, our observations indicate that the in vitro model making use of $\mathrm{CD} 154^{+}$cells as a surrogate for activated T cells (Van Kooten and Banchereau 2000), supplemented with cytokines, could be used to further investigate SLE B cells in the context of a high CD40 stimulus.

Additionally, as previously observed for normal B cells (de Grandmont et al. 2003), the proliferation and differentiation of SLE B cells were modulated by in vitro IVIg treatment. The comparison of IVIg treatment on HC and SLE B cells exposed to low and high levels of CD154 stimuli showed that proliferation was reduced, whereas IgG secretion rates increased in all the tested samples in the presence of IL-2, IL-4, and IL-10. Considerable evidence points to the inhibitory receptor Fc $\gamma$ RII (CD32) as an important cellular target of IVIg action (Nimmerjahn and Ravetch 2008); however, sig- naling through this negative $\mathrm{Fc}$ receptor is defective in SLE patients [reviewed in (Pugh-Bernard and Cambier 2006)]. As postulated before (de Grandmont et al. 2003; Dussault et al. 2008), IVIg could interact with other receptors on SLE B cells, possibly triggering their differentiation toward IgG secretion. A modest IVIg-induced enhancement of differentiation into $\mathrm{CD} 38^{++} \mathrm{CD} 138^{+}$cells is reported here for both SLE and control B cells. This observation required a low level of CD154 stimulation, since a high level of stimulation does not allow the emergence of $\mathrm{CD} 138^{+}$cells (Néron et al. 2005). In line with these results, the frequency of $9 \mathrm{G}^{+}$cells was also modulated following in vitro IVIg treatment of both control and four SLE samples. Transposed to the in vivo situation, where resources for survival following first-step activation are limited (Agenes et al. 2000), these observations suggest that anti-idiotypic antibodies present in IVIg could bind to 
A

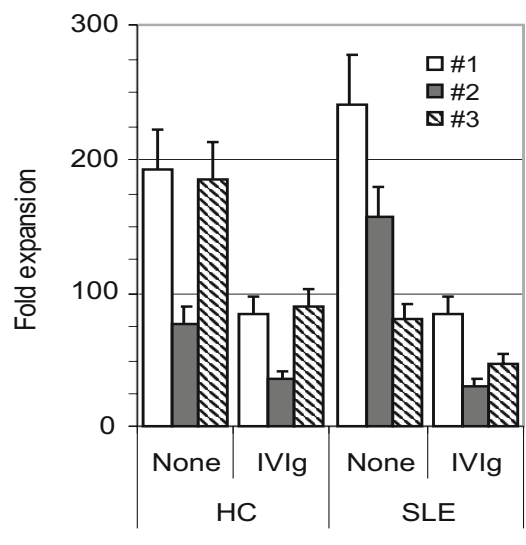

C

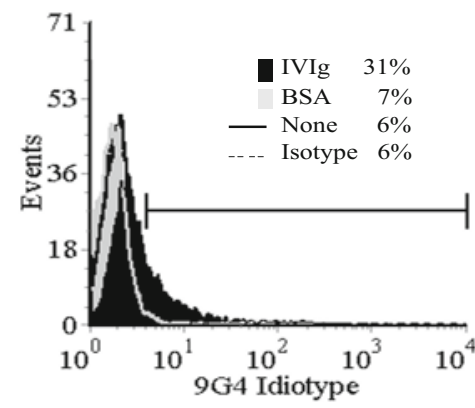

B

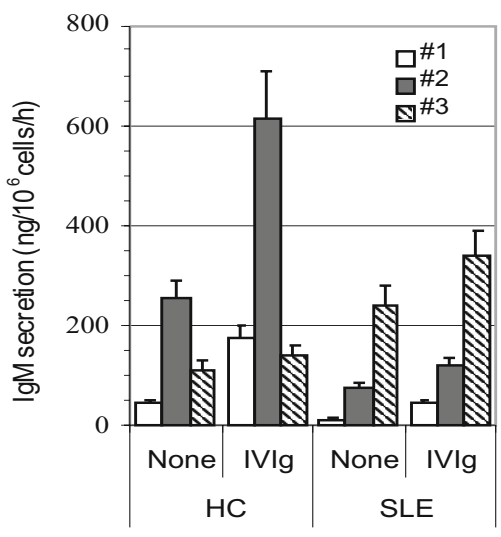

D

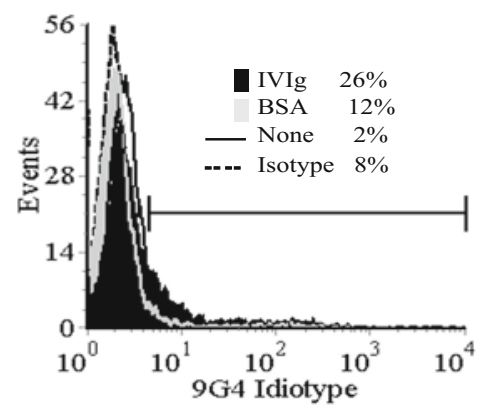

Fig. 5. IVIg enhances the expression of the $9 \mathrm{G} 4$ idiotype on B cells exposed to a high level of CD40 stimulation. Purified B cells from healthy controls (HC) and SLE patients (SLE) with SLEDAIs ranging from 2 to 9 were cultured under conditions of high CD154 interaction (ratio of 5 B cells per L4.5-CD154+ cell) in the presence of a mixture of IL-2, IL-4, IL-10, and $\mathrm{BAFF}$ and in the absence or presence of 10 $\mathrm{mg} / \mathrm{ml}$ IVIg. Cellular expansion and IgM secretion were determined as described above (Fig. 3). SLE B cells from patient nos. 29, 25, and 31 with the respective SLEDAIs of 2, 6, and 9 were monitored in three independent experiments $(\# 1, \# 2$ and \#3, respectively). (A) Total expansion of HC and SLE B cells stimulated in the presence (IVIg) or absence (None) of IVIg was evaluated on day 14. (B) IgM secretion rate by IVIg-treated and untreated (None) cells was evaluated at the end of the culture period. (C and $\mathbf{D})$ Expression of the 9G4 idiotype was determined in $\mathrm{HC}$ B cells (C) and SLE B cells from patient no. 27 (D) following IVIg treatment and compared with that of the control treatments (None and BSA). "Isotype" designates isotype control. Percentages indicate the the proportion of cells expressing the 9G4 idiotype following IVIg and control treatments. Results showed in panels $\mathrm{C}$ and $\mathrm{D}$ are representative of three supplemental experiment done with paired cultures of HC and SLE with samples from patient no. 25, 29, and 31 .
9G4+ autoreactive B cells and favor their deletion, as demonstrated in an SLE mouse model (Shoenfeld et al. 2002).

This study revealed for the first time that IVIg could act on SLE B cells under conditions of either low or high CD40 stimulus in the presence of IL-4 alone or in combination with IL-2 and IL-10. Furthermore, the effects of IVIg were observed even when BAFF (also known as BLyS), which is considered to be an important element in SLE pathology (Carter et al. 2005), was added to the cytokine cocktail. BAFF levels are elevated in the serum of SLE patients (up to $20 \mathrm{ng} / \mathrm{ml}$ ) (Cambridge et al. 2006; Zhang et al. 2001) and an IVIg-induced reduction in proliferation was observed even when SLE B cells were stimulated in the presence of similarly elevated BAFF concentrations $(25 \mathrm{ng} / \mathrm{ml})$.

Short- and long-lived plasma cells secreting pathogenic autoantibodies are an important target for the treatment of SLE (Dilillo et al. 2008; Grammer and Lipsky 2003; Radbruch et al. 2006). The fact that IVIg increased differentiation of SLE B cells toward plasma cells might seem contradictory. Interestingly, a recent study reporting that IVIg promotes immature plasma cell mobilization also showed that this was also a favorable prognostic marker for patients with Guillain-Barré syndrome and correlated with improved neurological function (Mori et al. 2008). These authors proposed that IVIg treatment induced a wave of newly formed plasma cells which can enter into competition with older plasma cells and re-equilibrate the repertoire of circulating antibody with nonpathogenic antibodies. Our results showing increased in vitro differentiation of B cells following IVIg treatment support their in vivo observations and are in agreement with their hypothesis. Therefore, these de novo IVIg-induced antibodies might further help in controlling the reactivities of pathogenic autoantibodies either by sequestering autoantigens or by mechanisms involving an idiotypic network, as proposed elsewhere (de Grandmont et al. 2003; Seite et al. 2008; Tha-In et al. 2008; Vani et al. 2008).

Overall, the in vitro CD40 activation system can be used as a model to further investigate the IVIg-induced modulation of SLE B cells. IVIg is usually administered as a salvage therapy for SLE patients who did not respond to standard treatment (Toubi et al. 2005; Sherer and Shoenfeld 2006a). Here we showed that IVIg can act on SLE B cells following their in vitro stimulation under conditions of high exposure to CD154, a system mimicking a hallmark of SLE in which sustained CD154 expression on T cells is observed (Koshy et al. 1996). Based on the observations described here, this in vitro model could be used to further investigate the role of IVIg-treated $\mathrm{B}$ cells in the modulation of various immune-cell populations, including plasma cells.

Acknowledgment: We are grateful to all the patients and healthy individuals who participated in this study and we thank C. Boulet and I. Gagnon of the Centre hospitalier universitaire 
de Sherbrooke and C. Côté, from Héma-Québec in Québec for the coordination of blood sample collection. We also thank É. Ducas for excellent technical assistance in B-cell culture as well as G. Côté and J. F. Fecteau for flow cytometric analyses. We are also thankful to F. K. Stevenson (Tenovus Research Laboratory) for the kind gift of the 9G4 monoclonal antibody and to J.-F. Leblanc for manuscript editing and revision. This work was supported by the Bayer-Talecris-CBS-Héma-Québec Partnership Fund.

\section{REFERENCES}

Agenes F, Rosado MM, Freitas AA (2000) Peripheral B cell survival. Cell Mol Life Sci 57:1220-1228

Anolik JH, Barnard J, Cappione A et al (2004) Rituximab improves peripheral B cell abnormalities in human systemic lupus erythematosus. Arthritis Rheum 50:3580-3590

Anthony RM, Nimmerjahn F, Ashline DJ et al (2008) Recapitulation of IVIG anti-inflammatory activity with a recombinant IgG Fc. Science 320:373-376

Arce E, Jackson DG, Gill MA et al (2001) Increased frequency of pre-germinal center b cells and plasma cell precursors in the blood of children with systemic lupus erythematosus. J Immunol 167:2361-2369

Banchereau J, de Paoli P, Valle A et al (1991) Long-term human B cell lines dependent on interleukin-4 and antibody to CD40. Science 251:70-72

Branch DW, Porter TF, Paidas MJ et al (2001) Obstetric uses of intravenous immunoglobulin: Successes, failures, and promises. J Allergy Clin Immunol 108:S133-S138

Cambridge G, Leandro MJ, Teodorescu M et al (2006) B cell depletion therapy in systemic lupus erythematosus - effect on autoantibody and antimicrobial antibody profiles. Arthritis Rheum 54:3612-3622

Cappione AJ, Pugh-Bernard AE, Anolik JH et al (2004) Lupus IgG V(H)4.34 antibodies bind to a $220-\mathrm{kDa}$ glycoform of CD45/B220 on the surface of human B lymphocytes. J Immunol 172:4298-4307

Carter RH, Zhao H, Liu X et al (2005) Expression and occupancy of BAFF-R on B cells in systemic lupus erythematosus. Arthritis Rheum 52:3943-3954

de Grandmont MJ, Racine C, Roy A et al (2003) Intravenous immunoglobulins induce the in vitro differentiation of human B lymphocytes and the secretion of IgG. Blood 101: 3065-3073

Dilillo DJ, Hamaguchi Y, Ueda Y et al (2008) Maintenance of long-lived plasma cells and serological memory despite mature and memory b cell depletion during CD20 immunotherapy in mice. J Immunol 180:361-371

Driver CB, Ishimori M, Weisman MH (2008) The B cell in systemic lupus erythematosus: a rational target for more effective therapy. Ann Rheum Dis 67:1374-1381

Dussault N, Ducas E, Racine C et al (2008) Immunomodulation of human $\mathrm{B}$ cells following treatment with intravenous immunoglobulins involves increased phosphorylation of extracellular signal-regulated kinases 1 and 2. Int Immunol 20:1369-1379
Fecteau JF, Néron S (2003) CD40 stimulation of human peripheral B lymphocytes: distinct response from naïve and memory cells. J Immunol 171:4621-4629

Gladman DD, Goldsmith CH, Urowitz MB et al (2000): The Systemic Lupus International Collaborating Clinics/American College of Rheumatology (SLICC/ACR) damage index for systemic lupus erythematosus international comparison. J Rheumatol 27:373-376

Gonzalez-Amaro R, Portales-Perez D, Baranda L et al (1998) Role of IL-10 in the abnormalities of early cell activation events of lymphocytes from patients with systemic lupus erythematosus. J Autoimmun 11:395-402

Grammer AC, Lipsky PE (2002) CD154-CD40 interactions mediate differentiation to plasma cells in healthy individuals and persons with systemic lupus erythematosus. Arthritis Rheum 46:1417-1429

Grammer AC, Lipsky PE (2003) B cell abnormalities in systemic lupus erythematosus. Arthritis Res Ther 5(suppl 4):S22-27

Grammer AC, Slota R, Fischer R et al (2003) Abnormal germinal center reactions in systemic lupus erythematosus demonstrated by blockade of CD154-CD40 interactions. J Clin Invest 112:1506-1520

Harada Y, Kawano MM, Huang N et al (1996) Identification of early plasma cells in peripheral blood and their clinical significance. Br J Haematol 92:184-191

Harigai M, Hara M, Fukasawa C et al (1999) Responsiveness of peripheral blood B cells to recombinant CD40 ligand in patients with systemic lupus erythematosus. Lupus 8:227-233

Hawker G, Gabriel S, Bombardier C et al (1993) A reliability study of SLEDAI: a disease activity index for systemic lupus erythematosus. J Rheumatol 20:657-660

Hochberg MC (1997) Updating the American College of Rheumatology revised criteria for the classification of systemic lupus erythematosus. Arthritis Rheum 40:1725

Isenberg DA, McClure C, Farewell V et al (1998) Correlation of 9G4 idiotope with disease activity in patients with systemic lupus erythematosus. Ann Rheum Dis 57:566-570

Jacobi AM, Odendahl M, Reiter K et al (2003) Correlation between circulating CD27(high) plasma cells and disease activity in patients with systemic lupus erythematosus. Arthritis Rheum 48:1332-1342

Kaveri SV, Dietrich G, Hurez V et al (1991) Intravenous immunoglobulins (IVIg) in the treatment of autoimmune diseases. Clin Exp Immunol 86:192-198

Kazatchkine MD, Dietrich G, Hurez V et al (1994) V region-mediated selection of autoreactive repertoires by intravenous immunoglobulin (i.v.Ig). Immunol Rev 139:79-107

Klinman DM, Shirai A, Conover J et al (1994) Cross-reactivity of IgG anti-DNA-secreting B cells in patients with systemic lupus erythematosus. Eur J Immunol 24:53-58

Koshy M, Berger D, Crow MK (1996) Increased expression of CD40 ligand on systemic lupus erythematosus lymphocytes. J Clin Invest 98:826-837

Le Pottier L, Bendaoud B, Dueymes M et al (2007) BAFF, a new target for intravenous immunoglobulin in autoimmunity and cancer. J Clin Immunol 27:257-265 
Liang MH, Socher SA, Larson MG et al (1989) Reliability and validity of six systems for the clinical assessment of disease activity in systemic lupus erythematosus. Arthritis Rheum 32:1107-1118

Mandik-Nayak L, Ridge N, Fields M et al (2008) Role of $\mathrm{B}$ cells in systemic lupus erythematosus and rheumatoid arthritis. Curr Opin Immunol 20:639-645

McHeyzer-Williams LJ, Malherbe LP, McHeyzer-Williams MG (2006) Checkpoints in memory B-cell evolution. Immunol Rev 211:255-268

Morell A (1997) Pharmacokinetics of intravenous immunoglobulin preparations. In: Lee ML, Strand V (eds) Intravenous immunoglobulins in clinical practice. Marcel Dekker, Inc., New-York, NY, pp 1-18

Mori I, Parizot C, Dorgham K et al (2008) Prominent plasmacytosis following intravenous immunoglobulin correlates with clinical improvement in Guillain-Barre syndrome. PLoS ONE 3:e2109

Nagafuchi H, Shimoyama Y, Kashiwakura J et al (2003) Preferential expression of B7.2 (CD86), but not B7.1 (CD80), on $\mathrm{B}$ cells induced by CD40/CD40L interaction is essential for anti-DNA autoantibody production in patients with systemic lupus erythematosus. Clin Exp Rheumatol 21:71-77

Negi VS, Elluru S, Siberil S et al (2007) Intravenous immunoglobulin: An update on the clinical use and mechanisms of action. J Clin Immunol 27:233-245

Néron S, Dussault N, Racine C (2006) Whole-blood leukoreduction filters are a source for cryopreserved cells for phenotypic and functional investigations on peripheral blood lymphocytes. Transfusion 46:537-544

Néron S, Pelletier A, Chevrier MC et al (1996) Induction of LFA-1 independent human B cell proliferation and differentiation by binding of CD40 with its ligand. Immunol Invest 25:79-89

Néron S, Racine C, Roy A et al (2005) Differential responses of human B-lymphocyte subpopulations to graded levels of CD40-CD154 interaction. Immunology 116:454-463

Néron S, Thibault L, Dussault N et al (2007) Characterization of mononuclear cells remaining in the leukoreduction system chambers of apheresis instruments after routine platelet collection: a new source of viable human blood cells. Transfusion 47:1042-1049

Nimmerjahn F, Ravetch JV (2008) Fcgamma receptors as regulators of immune responses. Nat Rev Immunol 8:34-47

Odendahl M, Jacobi A, Hansen A et al (2000) Disturbed peripheral B lymphocyte homeostasis in systemic lupus erythematosus. J Immunol 165:5970-5979

Pugh-Bernard AE, Cambier JC (2006) B cell receptor signaling in human systemic lupus erythematosus. Curr Opin Rheumatol 18:451-455

Pugh-Bernard AE, Silverman GJ, Cappione AJ et al (2001) Regulation of inherently autoreactive VH4-34 B cells in the maintenance of human B cell tolerance. J Clin Invest 108:1061-1070

Putterman C (2004) New approaches to the renal pathogenicity of anti-DNA antibodies in systemic lupus erythematosus. Autoimmun Rev 3:7-11
Radbruch A, Muehlinghaus G, Luger EO et al (2006) Competence and competition: the challenge of becoming a long-lived plasma cell. Nat Rev Immunol 6:741-750

Roy A, Krzykwa E, Lemieux R et al (2001) Increased efficiency of gamma-irradiated versus mitomycin C-treated feeder cells for the expansion of normal human cells in long-term cultures. J Hematother Stem Cell Res 10:873-880

Sato S, Fujimoto M, Hasegawa M et al (2004) Altered blood B lymphocyte homeostasis in systemic sclerosis: expanded naive B cells and diminished but activated memory B cells. Arthritis Rheum 50:1918-1927

Seite JF, Shoenfeld Y, Youinou P et al (2008) What is the contents of the magic draft IVIg? Autoimmun Rev 7:435-439

Sherer Y, Shoenfeld Y (2006a) Intravenous immunoglobulin for immunomodulation of systemic lupus erythematosus. Autoimmun Rev 5:153-155

Sherer Y, Shoenfeld Y (2006b) Mechanisms of disease: atherosclerosis in autoimmune diseases. Nat Clin Pract Rheumatol 2:99-106

Shoenfeld Y, Katz U (2005) IVIg therapy in autoimmunity and related disorders: our experience with a large cohort of patients. Autoimmunity 38:123-137

Shoenfeld Y, Rauova L, Gilburd B et al (2002) Efficacy of IVIG affinity-purified anti-double-stranded DNA anti-idiotypic antibodies in the treatment of an experimental murine model of systemic lupus erythematosus. Int Immunol 14:1303-1311

Sun KH, Yu CL, Tang SJ et al (2000) Monoclonal anti-double-stranded DNA autoantibody stimulates the expression and release of IL-1beta, IL-6, IL-8, IL-10 and TNF-alpha from normal human mononuclear cells involving in the lupus pathogenesis. Immunology 99:352-360

Tangye SG, Bryant VL, Cuss AK et al (2006) BAFF, APRIL and human B cell disorders. Semin Immunol 18:305-317

Tha-In T, Bayry J, Metselaar HJ et al (2008) Modulation of the cellular immune system by intravenous immunoglobulin. Trends Immunol 29:608-615

Toubi E, Kessel A, Shoenfeld Y (2005) High-dose intravenous immunoglobulins: an option in the treatment of systemic lupus erythematosus. Hum Immunol 66:395-402

Toubi E, Shoenfeld Y (2004a) BLyS/BAFF: a potential target in the treatment of active systemic lupus erythematosus. Isr Med Assoc J 6:99-102

Toubi E, Shoenfeld Y (2004b) The role of CD40-CD154 interactions in autoimmunity and the benefit of disrupting this pathway. Autoimmunity 37:457-464

Van Kooten C, Banchereau J (2000) CD40-CD40 ligand. J Leukoc Biol 67:2-17

Vani J, Elluru S, Negi VS et al (2008) Role of natural antibodies in immune homeostasis: IVIg perspective. Autoimmun Rev $7: 440-444$

Wei C, Anolik J, Cappione A et al (2007) A new population of cells lacking expression of CD27 represents a notable component of the B cell memory compartment in systemic lupus erythematosus. J Immunol 178:6624-6633 
Wouters CH, Diegenant C, Ceuppens JL et al (2004) The circulating lymphocyte profiles in patients with discoid lupus erythematosus and systemic lupus erythematosus suggest a pathogenetic relationship. Br J Dermatol 150:693-700

Zandman-Goddard G, Levy Y, Shoenfeld Y (2005) Intravenous immunoglobulin therapy and systemic lupus erythematosus. Clin Rev Allergy Immunol 29:219-228
Zhang J, Roschke V, Baker KP et al (2001) Cutting edge: a role for B lymphocyte stimulator in systemic lupus erythematosus. J Immunol 166:6-10

Zimmerman R, Radhakrishnan J, Valeri A et al (2001) Advances in the treatment of lupus nephritis. Ann Rev Med 52:63-78

Zouali M (2005) Taming lupus. Sci Am 292:58-65 